\title{
Don't forget our dual public health crises
}

Dear Editor:

The COVID-19 pandemic has changed our lives in ways that would previously have been thought unimaginable. Governments have enacted sweeping measures to keep citizens physically distanced. Public places remain empty. Hospitals ration resources that we never previously considered scarce.

During this unprecedented time, it is important that we do not forget that another emergency, the opioid overdose crisis, continues to smolder on. Presently, British Columbia has declared two active public health emergencies due to opioid-related overdose deaths (April 14, 2016), and the COVID-19 pandemic (March 17, 2020). ${ }^{1,2}$ Challenging times expose society's most vulnerable members; among them are people who use drugs who are disproportionately affected by both emergencies.

We must not forget our obligation to advocate and care for our patients at risk for opioid overdose. People with opioid addiction still come through our emergency departments. Just as we would not withhold insulin from patients with diabetic ketoacidosis, people with opioid use disorder should be considered for opioid agonist therapy, offered take-home naloxone kits, and linked with follow-up addictions care.

During these times, our advocacy for harm reduction approaches is more important than ever. We need to recognize the needs of people who use drugs to stay safe and healthy. This includes providing clean needles and pipes, and finding safe ways for people not to use alone (e.g., with others at a distance). ${ }^{3} \mathrm{We}$ must enable people who use drugs to self-isolate by providing a secure place to stay if they are unstably housed, and safe access to the substances to which they are addicted. Prescriber guidelines in Vancouver Coastal Health and British Columbia encourage opioid agonist therapies, and as another option, oral hydromorphone or extended release morphine for people with opioid use disorder. ${ }^{4}$

As emergency physicians and resuscitation experts, we are at the forefront of ever-changing best practice guidelines on patient management and provider protection during a COVID-19 world. We must share our knowledge and expertise to guide lay responders, peers, and workers at supervised injection sites who worry about their safety while responding to opioid overdoses. BC Centre for Disease Control recommendations for community responders emphasize higher initial naloxone doses, hand hygiene, and environmental cleaning at overdose prevention sites.

As emergency physicians, our calling has always been to support the most vulnerable in society. Now, more than ever, we must not forget our advocacy for people at risk for opioid overdose.

Jessica Moe, MD, MA, MSc

From the Department of Emergency Medicine, University of British Columbia, Vancouver, BC, Canada; Department of Emergency Medicine, Vancouver General Hospital, Vancouver, BC

Jane A. Buxton, MBBS, MHSc

From the British Columbia Centre for Disease Control, Vancouver, BC, Canada; School of Population and Public Health, University of British Columbia, Vancouver, BC

Keywords: COVID-19, emergency medicine, opioid epidemic, public health

Competing interests: None declared.

\section{REFERENCES}

1. Province of British Columbia. Provincial health officer declares public health emergency. 2016. Available at: https://news.gov.bc.ca/releases/2016 HLTH0026-000568 (accessed April 7, 2020).

2. Province of British Columbia. Province declares state of emergency to support COVID-19 response. 2020. Available at: https://news.gov.bc.ca/releases/ 2020PSSG0017-000511 (accessed April 7, 2020).

3. BC Centre for Disease Control. COVID-19: harm reduction and overdose response. 2020. Available at: http://www.bccdc.ca/Health-Info-Site/ Documents/COVID19-harm-reduction. pdf (accessed April 7, 2020).

Correspondence to: Dr. Jessica Moe, Department of Emergency Medicine, Vancouver General Hospital, 920 West 10th Avenue, Vancouver, British Columbia, CANADA, V5Z 1M9; Email: jessica.moe@gmail.com

(c) Canadian Association of Emergency Physicians 2020

CJEM 2020;22(4):1-2

DOI 10.1017/cem.2020.369 
4. BC Centre on Substance Use. Risk mitigation in the context of dual public health emergencies. 2020. Available at: https://www.bccsu.ca/wp-content/ uploads/2020/04/Risk-Mitigation-inthe-Context-of-Dual-Public-Health-
Emergencies-v1.4.pdf (accessed April 7, 2020). 